\title{
Periradicular Infiltration of the Cervical Spine: How New CT Scanner Techniques and Protocol Modifications Contribute to the Achievement of Low-Dose Interventions
}

\author{
Periradikuläre Infiltrationstherapie der Halswirbelsäule: \\ Wie die Technik neuer CT Scanner und Modifikationen des \\ Untersuchungsprotokolls zur Durchführung von low-dose- \\ Interventionen beitragen
}

Authors

Fabian Henry Jürgen Elsholtz, Julia Evi-Katrin Kamp, Janis Lucas Vahldiek, Bernd Hamm, Stefan Markus Niehues

\section{Affiliation}

Institute of Radiology, Campus Benjamin Franklin, CharitéUniversitätsmedizin Berlin, corporate member of Freie Universität Berlin, Humboldt-Universität zu Berlin, Germany

Key words

interventional radiology, computed tomography, spine, cervical, injection, radiation dosage

received 04.10.2017

accepted 16.05.2018

Bibliography

DOI https://doi.org/10.1055/a-0632-3930

Published online: 18.6.2018

Fortschr Röntgenstr 2019; 191: 54-61

(c) Georg Thieme Verlag KG, Stuttgart · New York

ISSN 1438-9029

Correspondence

Fabian Henry Jürgen Elsholtz

Klinik für Radiologie, Charité - Universitätsmedizin Berlin,

Hindenburgdamm 30, 12203 Berlin, Germany

Tel.: ++49/30/84453041

fabian.elsholtz@charite.de

\section{ZUSAMMENFASSUNG}

Ziel Die CT-gestützte periradikuläre Infiltrationstherapie der Halswirbelsäule stellt eine effektive symptomatische Behandlungsmethode bei Patienten mit Radikulopathie-bedingtem Schmerzsyndrom dar. Diese Studie evaluiert die Robustheit und Sicherheit eines low-dose-Protokolls bei einem CT Scanner mit iterativer Rekonstruktionssoftware.

Material und Methoden 183 Patienten nach periradikulärer Infiltrationstherapie der Halswirbelsäule wurden in diese Studie eingeschlossen. 82 Interventionen wurden auf einem neuem CT Scanner mit neuem Protokoll und Einsatz eines iterativen Rekonstruktionsalgorithmus durchgeführt. Spot Scanning wurde zur Planung eingesetzt und während der Fluoroskopie ein Basis-Setup von $80 \mathrm{kVp}$ und $5 \mathrm{mAs}$ verwen- det. Die Vergleichsgruppe umfasste 101 zuvor durchgeführte Interventionen mit einem CT Scanner ohne iterative Rekonstruktionssoftware. Das Dosis-Längen-Produkt, die Anzahl der Akquisitionen, die Schmerzreduktion anhand einer numerischen Analogskala und eventuelle Protokolländerungen zur sicheren Durchführung der Intervention wurden registriert.

Ergebnisse Das mediane DLP für die gesamte Intervention betrug 24,3 $\mathrm{mGy}^{*} \mathrm{~cm}$ in der Vergleichsgruppe und 1,8 $\mathrm{mGy}^{*} \mathrm{~cm}$ in der Studiengruppe. Die mediane Schmerzreduktion betrug -3 in der Studiengruppe und -2 in der Vergleichsgruppe. Eine Erhöhung des Röhrenstrom-Zeit-Produktes um $5 \mathrm{mAs}$ war bei 5 Patienten der Studiengruppe erforderlich.

Schlussfolgerung Die Einführung eines neuen CT Scanners mit einem neuen Interventionsprotokoll führte zur einer Dosisreduktion um 92,6\% ohne Einbußen in Sicherheit und Schmerzreduktion. Die benötigte Dosis liegt mehr als $75 \%$ unter den benötigten Dosen vergleichbarer Interventionen, die in bisherigen Studien veröffentlicht wurden. Eine Erhöhung des Röhrenstrom-Zeit-Produktes war in nur $6 \%$ der Interventionen notwendig.

\section{Kernaussagen:}

- Das vorgestellte Ultra-low-dose-Protokoll ermöglicht eine signifikante Dosisreduktion ohne Minderung des Therapieerfolges.

- Das Protokoll beinhaltet Spot Scanning zur Interventionsplanung und ein Basis Setup von 80 kVp und 5 mAs.

- Während der Fluoroskopie ist ein iterativer Rekonstruktionsalgorithmus aktiviert.

\section{ABSTRACT}

Purpose CT-guided periradicular infiltration of the cervical spine is an effective symptomatic treatment in patients with radiculopathy-associated pain syndromes. This study evaluates the robustness and safety of a low-dose protocol on a CT scanner with iterative reconstruction software.

Materials and Methods A total of 183 patients who underwent periradicular infiltration therapy of the cervical spine 
were included in this study. 82 interventions were performed on a new CT scanner with a new intervention protocol using an iterative reconstruction algorithm. Spot scanning was implemented for planning and a basic low-dose setup of $80 \mathrm{kVp}$ and $5 \mathrm{mAs}$ was established during intermittent fluoroscopy. The comparison group included 101 prior interventions on a scanner without iterative reconstruction. The dose-length product (DLP), number of acquisitions, pain reduction on a numeric analog scale, and protocol changes to achieve a safe intervention were recorded.

Results The median DLP for the whole intervention was 24.3 mGy* $\mathrm{cm}$ in the comparison group and $1.8 \mathrm{mGy}^{*} \mathrm{~cm}$ in the study group. The median pain reduction was -3 in the study group and -2 in the comparison group. A $5 \mathrm{mAs}$ increase in the tube current-time product was required in 5 patients of the study group.

Conclusion Implementation of a new scanner and intervention protocol resulted in a $92.6 \%$ dose reduction without a compromise in safety and pain relief. The dose needed here is more than $75 \%$ lower than doses used for similar interventions in published studies. An increase of the tube currenttime product was needed in only $6 \%$ of interventions.

\section{Key Points:}

- The presented ultra-low-dose protocol allows for a significant dose reduction without compromising outcome.

- The protocol includes spot scanning for planning purposes and a basic setup of $80 \mathrm{kVp}$ and $5 \mathrm{mAs}$.

- The iterative reconstruction algorithm is activated during fluoroscopy.

\section{Citation Format}

- Elsholtz FH, Kamp JE, Vahldiek JL et al. Periradicular Infiltration of the Cervical Spine: How New CT Scanner Techniques and Protocol Modifications Contribute to the Achievement of Low-Dose Interventions. Fortschr Röntgenstr 2019; 191: 54-61

\section{Introduction}

Periradicular infiltration therapy is an effective symptomatic treatment performed in patients with radiculopathy-associated pain syndromes [1]. Periradicular infiltration therapy has shown to be especially effective in patients with underlying disc prolapse, which is among the most frequent causes of cervical radiculopathy $[2,3]$. It is an interventional procedure that is offered to patients in whom conservative measures such as drug treatment have been exhausted [4]. Recent studies suggest that the outcome is best when both strategies are combined [5]. Unlike epidural space infiltration (ESI), periradicular infiltration is a targeted procedure with side-specific nerve root infiltration [6].

The intervention can be performed with or without imaging guidance. While conventional fluoroscopy is still the standard modality, the sectional imaging modalities CT and MRI are also well evaluated. CT is receiving more and more acceptance in the interventional routine and it has also been implemented to guide pain management [8]. Its wide use has also raised concerns in terms of radiation exposure for patients and interventionalists [9-12] and much research effort has been spent on dose reduction in diagnostic and also interventional CT [13-15].

Approaches to lowering the radiation dose of CT involve modifications of acquisition parameters such as tube current-time product, tube voltage and acquisition coverage [16]. More recently, the use of state-of-the-art image reconstruction software beyond standard filtered back projection (FBP) facilitates the restoring of image quality in low-dose scans $[17,18]$. The effective combination of all these options while monitoring clinical outcome is the main focus of this study.

\section{Materials and Methods}

\section{Patients}

The Institutional Review Board (IRB) approved this retrospective study, which included 183 patients - 82 patients in the study group and 101 patients in the comparison group. All patients underwent single-site periradicular infiltration therapy of the cervical spine for pain relief. The inclusion criteria were age over 18 years, focal neurological symptoms caused by cervical nerve root compression, and no prior surgical or interventional therapy. Informed consent was obtained.

\section{Patient groups and CT protocols}

Periradicular infiltration in the study group was accomplished with image guidance on an 80-slice CT scanner (Toshiba Aquilion PRIME, Toshiba Medical Systems, Ottawara, Japan) equipped with the adaptive iterative dose reduction (AIDR $3 \mathrm{D}$ ) iterative reconstruction software (Toshiba Medical Systems, Ottawara, Japan). Patients were positioned supine. Acquisition of a lateral scanogram was followed by small volume spot scanning of the segment to be treated ( $\triangleright$ Fig. 1 ). Spot scanning means a single volume acquisition with reconstruction of 4 images each with a 1 -mm slice thickness ( $100 \mathrm{kV}_{\mathrm{p}}$ and $10 \mathrm{mAs}, 0.5 \mathrm{~s}$ rotation time). The step-andshoot technique (intermittent fluoroscopy at $80 \mathrm{kV}_{\mathrm{p}}$ and $5 \mathrm{mAs}$, $0.5 \mathrm{~s}$ rotation time, slice thickness $4 \mathrm{~mm}$ ) allowed correct advancement of the needle ( $\triangleright$ Fig. 2) [19]. If image quality was insufficient (poor delineation of needle and/or neuroforamen), the tube current-time product was raised in increments of $5 \mathrm{mAs}$ ("bottom-up strategy").

The protocol used in the comparison group differed from the protocol in the study group as follows: CT guidance was performed on a 64-slice scanner (Siemens SOMATOM Definition, first Generation Dual Source Scanner, 2005, Siemens Healthcare, 

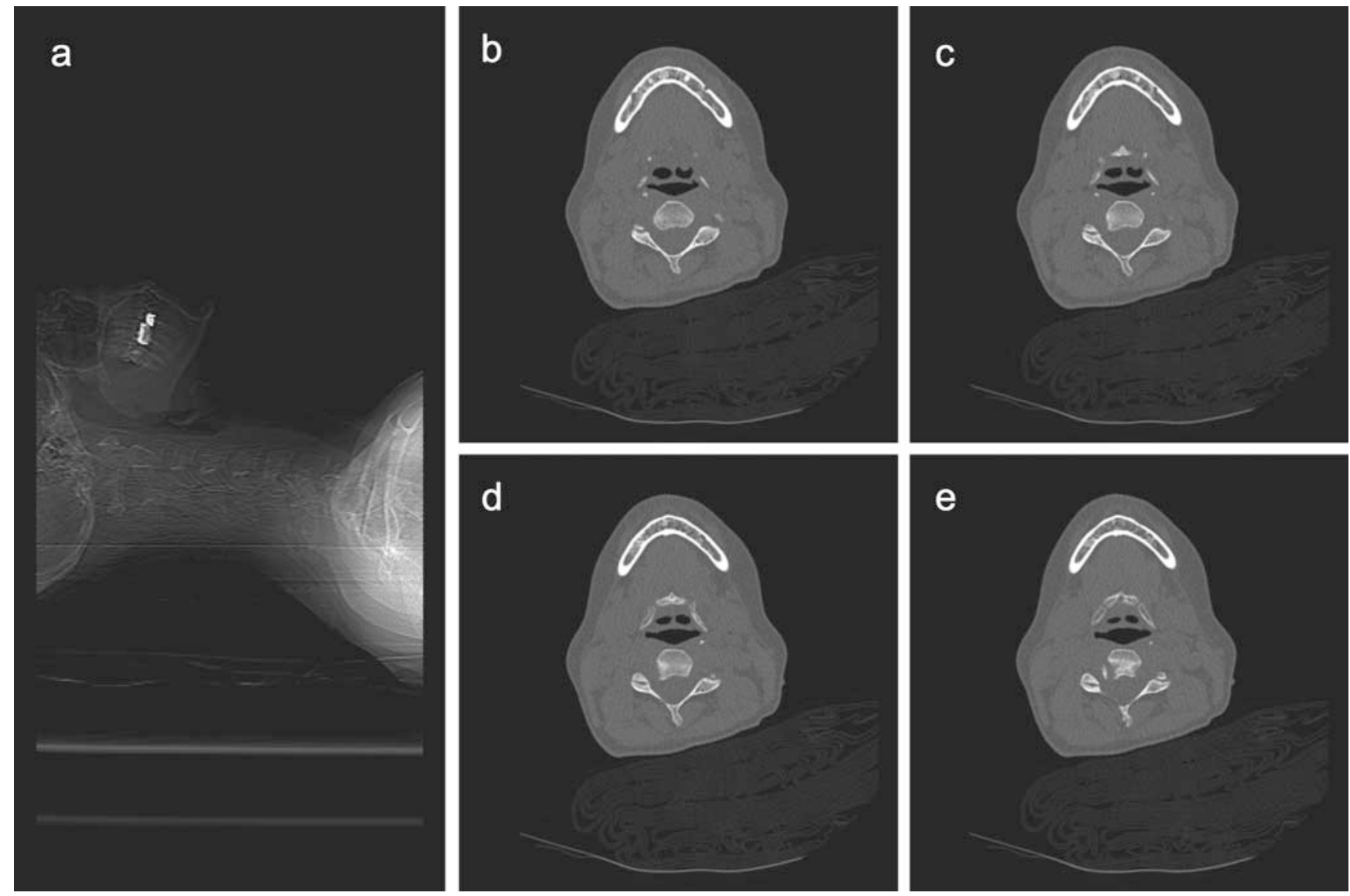

- Fig. 1 a-e 45 -year-old female patient scheduled for periradicular infiltration on the right side of the $C 2 / 3$ segment. Planning includes a lateral scanogram a followed by spot scanning with acquisition of 4 axial images with a 1 -mm slice thickness $\mathbf{d}$, e of the spinal segment to be treated. The spot scanning DLP is here $0.80 \mathrm{mGy}^{*} \mathrm{~cm}$.

- Abb. 1 a-e 45 Jahre alte weibliche Patientin mit periradikulärer Infiltrationstherapie auf der rechten Seite im Segment HWK 2/3. Die Planung umfasst ein laterales Scanogramm a gefolgt von Spot Scanning durch Akquisition von 4 axialen Bildern in $1 \mathrm{~mm}$ Schichtdicke d, e des zu behandelnden Wirbelsäulensegmentes. Die Dosis des Spot Scanning beträgt hier $0,80 \mathrm{mGy}{ }^{*} \mathrm{~cm}$.

Erlangen, Germany) using standard image reconstruction with FBP. Small-volume spot scanning was not available on this scanner. For planning purposes, a scanogram was followed by a focal helical planning CT ( $100 \mathrm{kV}_{\mathrm{p}}$, automatic tube current modulation, $0.75-\mathrm{mm}$ slice thickness). The length of this acquisition was defined by the interventionalist. The interventional part differed from the study group only in terms of acquisition parameters (100 kV $\mathrm{V}_{\mathrm{p}}, 28 \mathrm{mAs}, 5 \mathrm{~mm}$ slice thickness).

There was no access to previous diagnostic imaging data in either group. Access was accomplished via the transforaminal route in all cases. Correct needle placement was confirmed with an injection of contrast medium $(0.5 \mathrm{ml}$ Hexabrix 320 , Guerbet, Roissy, France) diluted with a local anesthetic ( $2 \mathrm{ml}$ bupivacaine, Carbostesin $0.5 \%$, AstraZeneca GmbH, Wedel, Germany). Finally, the interventionalist administered the therapeutic injection of glucocorticoid (1 ml dexamethasone, Lipotalon, Merckle Recordati GmbH, Ulm, Germany).

The tube current-time product ( $\mathrm{mAs})$, tube voltage $\left(k \mathrm{~V}_{\mathrm{p}}\right)$, the resulting cumulative dose-length product (DLP) in $\mathrm{mGy}^{*} \mathrm{~cm}$, and the number of interventional acquisitions were documented for each intervention. For evaluation of the outcome, patients were asked to assess their average pain on a standardized numeric rating scale from 0 ("no pain") to 10 ("worst pain one can imagine") immediately before the intervention and again 6 weeks after.

To rule out experience bias in the two groups, radiologists with different work experience performed the interventions. In the study group, 54 interventions were performed by an experienced radiologist ( $A$ : 13 years of work experience) and 28 interventions by a resident radiologist ( $B$ : 3 years of work experience). In the comparison group the same radiologist A performed 69 interventions and another radiologist $C$ (also 3 years of work experience) performed 32 interventions.

\section{Data analysis}

\section{Statistics}

Statistical analysis was performed using base $\mathrm{R}$ (version 3.2.3, R Foundation for Statistical Computing, Vienna, Austria). Plots were generated using the lattice package.

First, the Shapiro-Wilk test was applied to test for normal distribution. As it indicated non-normal distribution, the nonpara- 

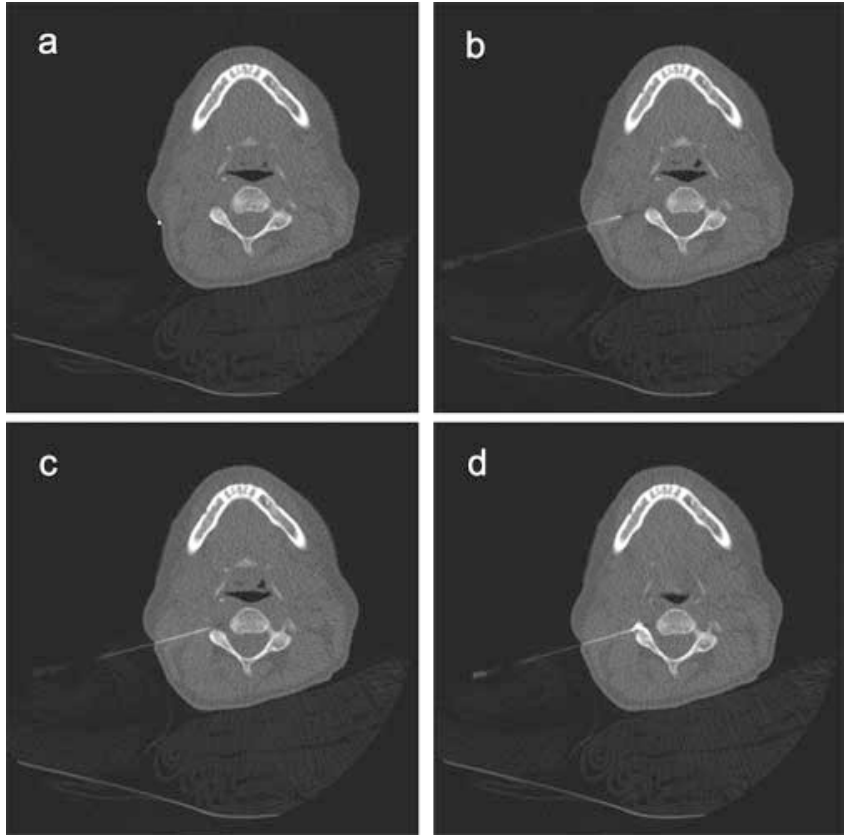

- Fig. 2 a-d Same patient as in Fig. 1. Periradicular infiltration on the right side of the $C 2 / 3$ segment. Axial views a-d acquired with a 4-mm slice thickness using the step-and-shoot technique. Image $d$ shows test injection with diluted contrast medium.

- Abb. 2 a-d Dieselbe Patientin wie in Abb. 1. Periradikuläre Infiltrationstherapie auf der rechten Seite im Segment HWK 2/3. Die Bilder in axialer Schichtführung a-d wurden mit $4 \mathrm{~mm}$ Schichtdicke unter Anwendung der step-and-shoot-Technik akquiriert. Bild d zeigt die Testinjektion mit verdünntem Kontrastmittel.

metric Wilcoxon rank-sum test was used to test for differences in variables between the two groups. The chi-squared test was used to test for differences in variables between the groups only with respect to sex. Statistical significance was assumed for $\mathrm{p}$-values $<0.05$.

\section{Dose}

The dose-length product (DLP) is the most common parameter for comparing radiation doses of CT examinations. It is calculated as the Computed Tomography Dose Index $\left(C T D I_{\text {vol }}\right)$ multiplied by the scan length:

$\mathrm{DLP}=\mathrm{CTDI}{ }^{*}$ scan length [unit: $\mathrm{mGy}{ }^{*} \mathrm{~cm}$ ]

DLP and $C T D I_{\text {vol }}$ are X-ray tube output metrics [20]. To estimate the dose absorbed by the patient in terms of population-based stochastic health risk, effective dose was introduced [21]. It is calculated by multiplying DLP with a tissue-specific conversion factor. In this study the current conversion factor for cervical spine imaging of 0.0057 [22] was applied:

$\mathrm{D}_{\text {eff }}=\frac{0.0057 \mathrm{mSv}}{\mathrm{mGy} \times \mathrm{cm}} \times \mathrm{DLP} \quad[$ unit: $\mathrm{mSv}]$

\section{Results}

Patient demographics are compiled in $>$ Table 1 and data on the treated spinal segments and body sides are presented in

- Table 2.

The total median DLP was significantly decreased from 24.30 mGy* $\mathrm{cm}$ (effective dose: $0.13 \mathrm{mSv}$ ) in the comparison group to $1.80 \mathrm{mGy}^{*} \mathrm{~cm}(0.01 \mathrm{mSv})$ in the study group, corresponding to a $92.6 \%$ reduction. The planning part accounted for $91 \%$ of the total DLP in the comparison group versus $44 \%$ in the study group. A significant dose reduction from $1.70 \mathrm{mGy}^{*} \mathrm{~cm}$ $(0.01 \mathrm{mSv})$ to $0.95 \mathrm{mGy}^{*} \mathrm{~cm}(0.005 \mathrm{mSv}, \mathrm{p}=0.01)$ was also accomplished for the interventional part. The median self-reported pain reduction was -3 in the study group and -2 in the comparison group; the difference was not significant $(p=0.80)$.

Differences in the level of experience between the radiologists performing the interventions had no effect on the DLP in the study group, which was a median of $1.80 \mathrm{mGy}^{*} \mathrm{~cm}$ for radiologists $A$ and $B$.

In the comparison group, the median DLP was $24.20 \mathrm{mGy}^{*} \mathrm{~cm}$ for radiologist $A$ and $28.90 \mathrm{mGy}^{*} \mathrm{~cm}$ for radiologist $\mathrm{B}$. The difference in overall dose was not significant in the study group $(p=0.48)$ or in the comparison group $(p=0.07)$.

A higher tube current-time product was necessary in 5 patients of the study group to achieve adequate demarcation of the neuroforamen. All of them were treated in the $C$ 6/7 segment ( $\triangleright$ Fig. 3).

- Table 3 compiles the results for all parameters measured in the two groups. In > Fig. 4, dose distributions for each step and group are juxtaposed. To represent these data in a single diagram, the $y$-axis had to be scaled as decadic logarithm of the DLP.

\section{Discussion}

Dose reduction in interventional $\mathrm{CT}$ remains a hot topic as the overall dose mirrors the cumulative ionizing radiation repeatedly applied to a focal region. Despite all efforts to reduce dose, safety must never be compromised. In our study we achieved an overall dose reduction for complete periradicular infiltration therapy that has not been accomplished before, both in our institutional comparison group and in previous studies reported in the literature. Moreover, this dose reduction has been accomplished without lowering patient safety during the intervention. Even if our study design provided a comparison group, the main aspect is the very low median dose level achieved in the study group. The scanner setup during intermittent fluoroscopy could even be optimized in terms of dose reduction with respect to recently published low-dose protocols for the lumbar spine on the same scanner $[14,15]$. This mainly refers to the smaller cervical body diameter where $80 \mathrm{kV}$ (towards $100 \mathrm{kV}$ ) is sufficient during intermittent fluoroscopy. In another comparable study Paik reported a median DLP of $7.92 \mathrm{mGy}^{*} \mathrm{~cm}$ for his own new protocol for cervical TFESI (Transforaminal Epidural Space Injection), which is similar to the periradicular infiltration therapy we performed in our study [23]. The median DLP of $1.80 \mathrm{mGy}^{*} \mathrm{~cm}$ in our study group, which corresponds to just $22.72 \%$ of the dose reported by Paik. Kranz et al. 
- Table 1 Demographic data of the patients included in the study group and in the comparison group. Wilcoxon rank sum test was used to test for statistically significant differences in age and BMI, and the chi-squared test for differences in sex.

- Tab.1 Demografische Daten der Patienten, die in die Studiengruppe und die Vergleichsgruppe eingeschlossen wurden. Der Wilcoxon Rangsummentest wurde zur Überprüfung der Signifikanz der Unterschiede für das Alter und den BMI angewendet, der Chi-Quadrat-Test hingegen für das Geschlecht.

\begin{tabular}{|c|c|c|c|c|c|}
\hline & \multicolumn{2}{|l|}{ study group } & \multicolumn{2}{|c|}{ comparison group } & p-value \\
\hline $\mathrm{N}$ & \multicolumn{2}{|l|}{82} & \multicolumn{2}{|l|}{101} & - \\
\hline sex & 29 female & 53 male & 66 female & 55 male & 0.06 \\
\hline age & 50 (median) & $34-67$ (range) & 54 (median) & $33-88$ (range) & 0.33 \\
\hline BMI & 27 (median) & $23-35$ (range) & 26 (median) & $22-33$ (range) & 0.29 \\
\hline
\end{tabular}

- Table 2 Cervical segments targeted in the study group and comparison group.

- Tab.2 Zervikale Zielsegmente in der Studiengruppe und Vergleichsgruppe.

\begin{tabular}{|l|r|r|r|r|}
\hline & \multicolumn{2}{|c|}{ study group } & \multicolumn{2}{c|}{ comparison group } \\
\hline side & left & right & left & right \\
\hline C 3/4 & 0 & 3 & 2 & 1 \\
\hline C 4/5 & 11 & 4 & 5 & 15 \\
\hline C 5/6 & 19 & 19 & 20 & 28 \\
\hline C 6/7 & 6 & 20 & 21 & 7 \\
\hline C 7/T 1 & 0 & 0 & 1 & 1 \\
\hline
\end{tabular}

published data on the safety and technique, including tube parameters, of cervical interlaminar ESI without mentioning overall dose [13]. They used a range of tube currents from 30 to 150 $\mathrm{mA}$, making it likely that overall doses were higher than accomplished in our study. In our study, we modified multiple parameters to achieve a dose reduction. First, acquisition of a volume for planning purposes (spot scanning) instead of a helical scan made a substantial contribution to dose reduction in our approach. Second, reducing the tube current-time product to its lowest possible level ( $5 \mathrm{mAs}$ ) was possible on the condition that the acquired images are not of diagnostic image quality but ensure safe completion of the intervention. If the safety criteria as explained above were not met, the dose had to be increased. Iterative reconstruction software is available on an increasing number of state-of-the-art CT scanners. We assume that the dose reduction achieved with the use of AIDR 3D in diagnostic imaging can also be exploited to reduce the dose in the interventional setting. Self-reported pain assessment by our patients strongly suggests that dose reduction did not impair the outcome of the intervention. Utilizing the numeric rating scale helped to objectify the success of the intervention and revealed no statisti-
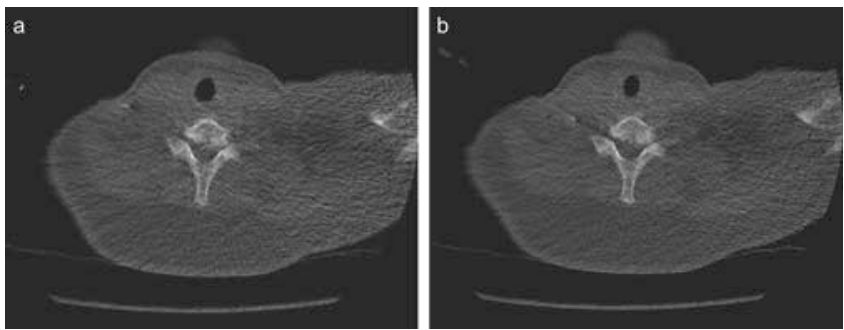

- Fig. 3 a, b 49-year-old female patient undergoing periradicular infiltration of the $\mathrm{C} 6$ / C7 segment on the right side. Axial views acquired with a 4-mm slice thickness. The basic setup of $80 \mathrm{kVp}$ and $5 \mathrm{mAs}$ a was rated to be insufficient to clearly define the targeted neuroforaminal area and vertebral artery position, which might preclude safe positioning of the needle. Use of $10 \mathrm{mAs} \mathbf{b}$ improved image quality and allowed adequate final positioning.

- Abb. 3 a, b 49 Jahre alte weibliche Patientin mit periradikulärer Infiltrationstherapie im Segment HWK 6/7 auf der rechten Seite. Axiale Bilder wurden mit $4 \mathrm{~mm}$ Schichtdicke akquiriert. Das Basis Setup von $80 \mathrm{kVp}$ und $5 \mathrm{mAs}$ a wurde als unzureichend eingeschätzt um die Zielstrukturen Neuroforamen und Position der Arteria vertebralis deutlich abzugrenzen. Dies hätte eine sichere Positionierung der Nadel beeinträchtigen können. Eine Erhöhung auf $10 \mathrm{mAs}$ b verbesserte die Bildqualität und erlaubte eine adäquate finale Positionierung.

cally significant difference between the study group and comparison group, even though we measured a reduction from -3 to -2 . Our interventional approach also fits into the current trend toward increased use of transforaminal access routes in periradicular infiltration therapy or ESI [24]. Therefore, the protocol presented here should be of interest to most interventional radiologists.

All 5 patients in whom the radiologists decided to raise the tube current time-product to $10 \mathrm{mAs}$ were treated in the $\mathrm{C} 6 / 7$ segment. Here, the poorer image quality is mainly attributable to the fact that the shoulder is in the acquisition field, so it might already have been apparent from the referral note that a higher tube current-time product would be needed in these patients. The number of acquisitions needed to complete the intervention corresponds linearly to the applied dose. 
- Table 3 Summary of dose and pain parameters. Wilcoxon rank sum test was used to test for statistically significant differences.

- Tab.3 Zusammenfassung der Dosis- und Schmerzparameter. Der Wilcoxon Rangsummentest wurde zur Überprüfung der Signifikanz der Unterschiede angewendet.

\begin{tabular}{|c|c|c|c|c|c|}
\hline & \multicolumn{2}{|c|}{ study group } & \multicolumn{2}{|c|}{ comparison group } & \multirow{3}{*}{ p-value } \\
\hline & \multirow[t]{2}{*}{ median } & range & \multirow[t]{2}{*}{ median } & \multirow{2}{*}{$\begin{array}{l}\text { range } \\
\text { (Q11-Q3) }\end{array}$} & \\
\hline & & (Q1-Q3) & & & \\
\hline $\begin{array}{l}\text { DLP planning } \\
\left(\mathrm{mG} y^{*} \mathrm{~cm}\right)\end{array}$ & 0.80 & $\begin{array}{l}0.80-0.80 \\
(0.80-0.80)\end{array}$ & 22.00 & $\begin{array}{l}4.00-27.00 \\
(16.00-27.00)\end{array}$ & $<0.01^{1}$ \\
\hline DLP intervention $\left(\mathrm{mGy}^{*} \mathrm{~cm}\right)$ & 0.95 & $\begin{array}{l}0.50-4.10 \\
(0.80-1.20)\end{array}$ & 1.70 & $\begin{array}{l}0.60-8.60 \\
(1.20-2.60)\end{array}$ & $<0.01^{1}$ \\
\hline acquisitions & 9.00 & $\begin{array}{l}2.00-25.00 \\
(8.00-12.00)\end{array}$ & 7.00 & $\begin{array}{l}4.00-33.00 \\
(8.00-15.00)\end{array}$ & $0.03^{1}$ \\
\hline DLP total $\left(\mathrm{mGy}^{*} \mathrm{~cm}\right)$ & 1.80 & $\begin{array}{l}1.30-4.90 \\
(1.60-2.00)\end{array}$ & 24.30 & $\begin{array}{l}7.60-312.90 \\
(18.50-29.20)\end{array}$ & $<0.01^{1}$ \\
\hline calculated total effective dose (mSv) & 0.01 & $\begin{array}{l}0.01-0.03 \\
(0.01-0.01)\end{array}$ & 0.139 & $\begin{array}{l}0.04-1.79 \\
(0.11-0.17)\end{array}$ & $<0.01^{1}$ \\
\hline pain before (NRS) & 7.00 & $\begin{array}{l}1.00-10.00 \\
(6.00-8.00)\end{array}$ & 7.00 & $\begin{array}{l}3.00-10.00 \\
(7.00-8.00)\end{array}$ & 0.10 \\
\hline pain after (NRS) & 4.00 & $\begin{array}{l}0.00-9.00 \\
(3.00-6.00)\end{array}$ & 5.00 & $\begin{array}{l}1.00-9.00 \\
(4.00-6.00)\end{array}$ & 0.06 \\
\hline pain relief (NRS) & -3.00 & $\begin{array}{l}-1.00--6.00 \\
(-1.00--4.00)\end{array}$ & -2.00 & $\begin{array}{l}-1.00--6.00 \\
(-1.00--3.00)\end{array}$ & 0.80 \\
\hline
\end{tabular}

In our study, there was no difference in overall dose between interventions performed by the more experienced radiologist $(A)$ and those performed by the resident radiologist (B). This finding indicates robustness of the protocol against different levels of work experience. Successful implementation of this protocol for periradicular interventions might contribute to dose reduction efforts in other CT-guided interventions in high-contrast regions such as bone biopsy, thoracocentesis, and lung biopsy. This expectation has been confirmed by initial experience with other interventions in our institution.

Our study has some limitations including the retrospective design. Mainly it compares interventional protocols performed on scanners of different generations and hence different technical features. While features of the modern scanner have nearly been exhausted to reduce dose, there would still have been room for adjustments in the protocol of the comparison group to also achieve significant dose reduction, e. g. a standardized length of the helical planning scan. Other features such as reducing the tube current-time product to $5 \mathrm{mAs}$ are not available on the older scanner. On this view the study design might look unfair but it also reflects the clinical reality we experienced. This study underlines the opportunity for significant protocol adjustments when new scanner generations replace older ones. Furthermore, more accurate dose estimates might have been obtained using a size- specific dose estimate (SSDE), which includes patient diameter for calculating radiation doses. However, as this dose estimate is not automatically available on most CT scanners and for better comparability with published data, we opted for DLP in our study. Our exemplary calculations of SSDE yielded even lower overall doses compared with DLP. Basically, the estimation of radiationinduced risks deriving from low-dose exposure remains unclear and still needs to be investigated. However, especially with patients tending to undergo multiple interventions, low-dose settings should be favored. The present study complies precisely with the ALARA principle ("as low as reasonably achievable") by which all dose-related considerations should be guided. Another issue is the measurement of pain. Self-reported pain before and 6 weeks after an intervention is a subjective measure of outcome. Functional scores and long-term surveys were not the focus of this study but could give important additional information on outcome. We used AIDR $3 \mathrm{D}$ to significantly reduce image noise $[25,26]$. Like other iterative reconstruction algorithms, it is vendor-specific and the results might be different with algorithms from other vendors. Future studies should focus on quantifying the dose reduction contribution of AIDR $3 \mathrm{D}$ in interventional procedures. Further dose reduction might be possible by reducing the number of spot scanning acquisitions to two or three. This is underlined by the case presented in $>$ Fig. $\mathbf{1}$, which shows that 


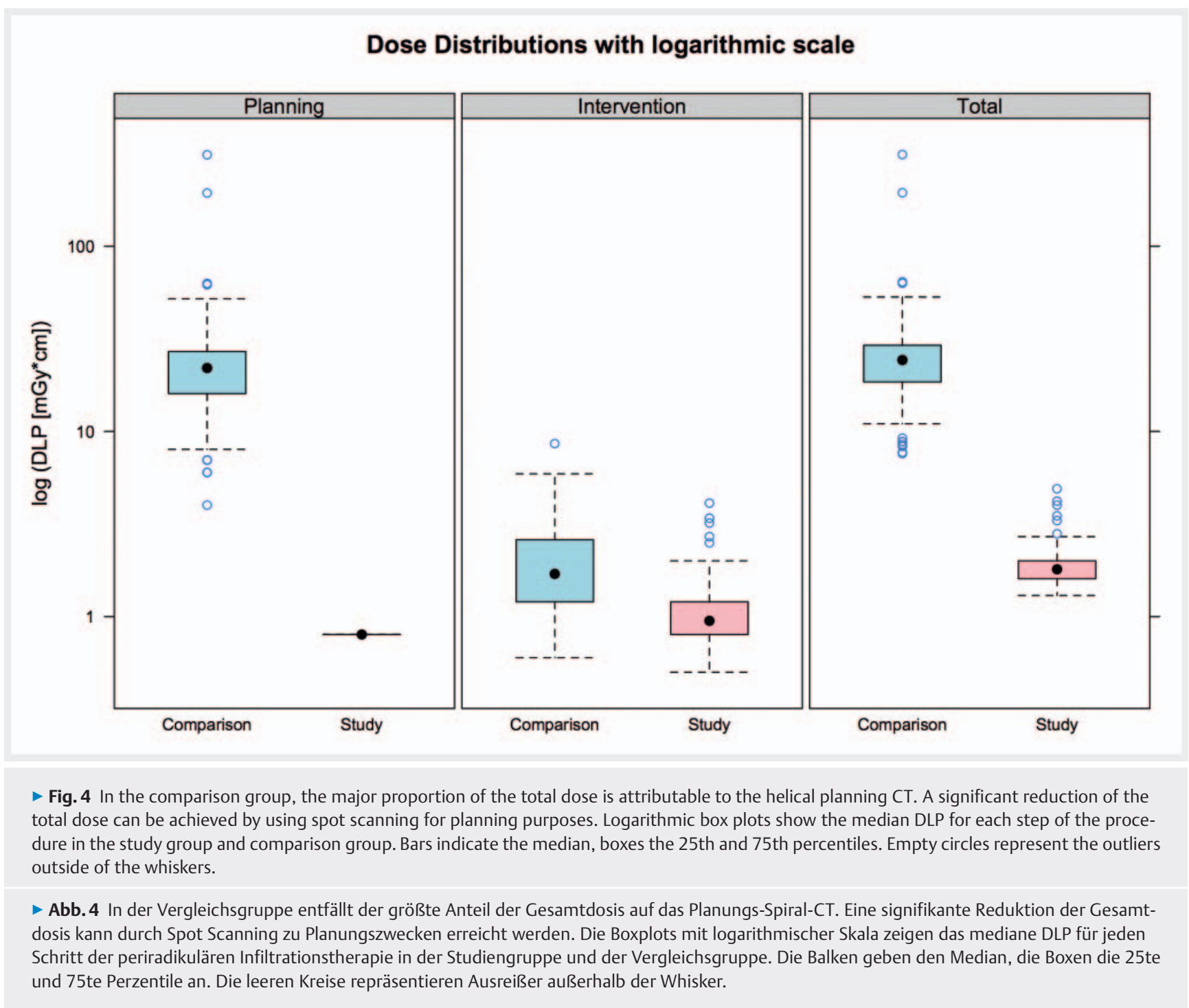

only images b and c would have been necessary to plan the intervention. Quantification of the contribution of the scanogram to the overall dose was not part of this or any previous study but may contribute to further dose reduction.

\section{Conclusion}

This study proposes a protocol for periradicular infiltration of the cervical spine combining spot scanning for planning purposes and a basic scanner setup of $80 \mathrm{kV}_{\mathrm{p}}, 5 \mathrm{mAs}$ for intermittent fluoroscopy with the use of an iterative image reconstruction algorithm. The median DLP $\left(1.80 \mathrm{mGy}^{*} \mathrm{~cm}\right)$ was more than $75 \%$ lower compared with earlier protocols reported in the literature (7.92 $\left.\mathrm{mGy}^{*} \mathrm{~cm}\right)$. Hence, it addresses the rising concern in terms of radiation exposure for patients and radiologists. In terms of selfreported pain, a considerable pain reduction of -3 on the numeric rating scale could be achieved.

\section{CLINICAL RELEVANCE}

- Detailed protocol optimization leads to a significant dose reduction in not only the diagnostic but also the interventional use of CT.

- This complies with the ALARA principle ("as low as reasonably achievable").

- Especially in periradicular infiltration therapy, patients tend to undergo multiple interventions and interventionalists are repeatedly exposed to radiation.

- Iterative reconstruction software is also useful in interventional protocols.

\section{Conflict of Interest}

The authors declare that they have no conflict of interest. 


\section{References}

[1] Oder B, Thurnher S. Periradicular infiltration therapy: Clinical indications, technique and results. Der Radiologe 2015; 55: 833-839. doi:10.1007| s00117-015-0017-2

[2] Yoon JY, Kwon JW, Yoon YC et al. Cervical interlaminar epidural steroid injection for unilateral cervical radiculopathy: comparison of midline and paramedian approaches for efficacy. Korean journal of radiology 2015; 16: 604 -612. doi:10.3348/kjr.2015.16.3.604

[3] Choi JW, Lim HW, Lee JY et al. Effect of Cervical Interlaminar Epidural Steroid Injection: Analysis According to the Neck Pain Patterns and MRI Findings. The Korean journal of pain 2016; 29: 96 -102. doi:10.3344/ kjp.2016.29.2.96

[4] Stout A. Epidural steroid injections for cervical radiculopathy. Physical medicine and rehabilitation clinics of North America 2011; 22: 149159. doi:10.1016/j.pmr.2010.10.007

[5] Cohen SP, Hayek S, Semenov Y et al. Epidural steroid injections, conservative treatment, or combination treatment for cervical radicular pain: a multicenter, randomized, comparative-effectiveness study. Anesthesiology 2014; 121: 1045 - 1055. doi:10.1097/aln.0000000000000409

[6] Palmer WE. Spinal Injections for Pain Management. Radiology 2016; 281: 669-688. doi:10.1148/radiol.2016152055

[7] Deml MC, Buhr M, Wimmer MD et al. CT-guided infiltration saves surgical intervention and fastens return to work compared to anatomical landmark-guided infiltration in patients with lumbosciatica. European journal of orthopaedic surgery \& traumatology: orthopedie traumatologie 2015; 25 (Suppl. 1): S177-S182. doi:10.1007/s00590-015-1602-9

[8] Maurer MH, Schreiter N, de Bucourt M et al. Cost comparison of nerve root infiltration of the lumbar spine under MRI and CT guidance. European radiology 2013; 23: 1487 -1494. doi:10.1007/s00330-012-2757-y

[9] Rogits B, Jungnickel K, Lowenthal D et al. Prospective Evaluation of the radiologist's hand dose in CT-guided interventions. RoFo: Fortschritte auf dem Gebiete der Rontgenstrahlen und der Nuklearmedizin 2013; 185: 1081 - 1088. doi:10.1055/s-0033-1350368

[10] Hall E], Brenner D]. Cancer risks from diagnostic radiology: the impact of new epidemiological data. The British journal of radiology 2012; 85: e1316-e1317. doi:10.1259/bjr/13739950

[11] Brenner D], Hall E]. Computed tomography-an increasing source of radiation exposure. The New England journal of medicine 2007; 357: 2277-2284. doi:10.1056/NEJMra072149

[12] Seals KF, Lee EW, Cagnon CH et al. Radiation-Induced Cataractogenesis: A Critical Literature Review for the Interventional Radiologist. Cardiovascular and interventional radiology 2016; 39: 151 -160. doi:10.1007| s00270-015-1207-z

[13] Kranz PG, Raduazo P, Gray L et al. CT fluoroscopy-guided cervical interlaminar steroid injections: safety, technique, and radiation dose parameters. AJNR 2012; 33: 1221 -1224. doi:10.3174/ajnr.A2954
[14] Elsholtz FH, Schaafs LA, Kohlitz T et al. Periradicular infiltration of the lumbar spine: testing the robustness of an interventional ultra-low-dose protocol at different body mass index levels. Acta radiologica (Stockholm, Sweden: 1987) 2017. doi:10.1177/0284185117694508

[15] Elsholtz FHJ, Schaafs LA, Erxleben C et al. Ultra-low-dose periradicular infiltration of the lumbar spine: spot scanning and its potential for further dose reduction by replacing helical planning CT. La Radiologia medica 2017. doi:10.1007/s11547-017-0766-2

[16] Trattner S, Pearson GD, Chin C et al. Standardization and optimization of $\mathrm{CT}$ protocols to achieve low dose. Journal of the American College of Radiology: JACR 2014; 11: 271 -278. doi:10.1016/j.jacr.2013.10.016

[17] Willemink M], de Jong PA, Leiner T et al. Iterative reconstruction techniques for computed tomography Part 1: technical principles. European radiology 2013; 23: 1623 - 1631. doi:10.1007/s00330-012-2765-y

[18] Willemink M], Leiner T, de Jong PA et al. Iterative reconstruction techniques for computed tomography part 2: initial results in dose reduction and image quality. European radiology 2013; 23: 1632-1642. doi:10.1007/s00330-012-2764-z

[19] Weininger M, Mills JC, Rumboldt Z et al. Accuracy of CT guidance of lumbar facet joint block. Am J Roentgenol 2013; 200: 673-676. doi:10.2214/ajr.12.8829

[20] Huda W, Mettler FA. Volume CT dose index and dose-length product displayed during CT: what good are they? Radiology 2011; 258: $236-$ 242. doi:10.1148/radiol.10100297

[21] [Anonym]. The 2007 Recommendations of the International Commission on Radiological Protection. ICRP publication 103. Annals of the ICRP 2007; 37: 1 -332. doi:10.1016/j.icrp.2007.10.003

[22] Shrimpton PC, Jansen JT, Harrison JD. Updated estimates of typical effective doses for common CT examinations in the UK following the 2011 national review. The British journal of radiology 2016; 89: 20150346. doi:10.1259/bjr.20150346

[23] Paik NC. Radiation Dose Reduction in CT Fluoroscopy-Guided Cervical Transforaminal Epidural Steroid Injection by Modifying Scout and Planning Steps. Cardiovascular and interventional radiology 2015. doi:10.1007/s00270-015-1230-0

[24] Andreisek G, Jenni M, Klingler D et al. Access routes and reported decision criteria for lumbar epidural drug injections: a systematic literature review. Skeletal radiology 2013; 42: 1683 - 1692. doi:10.1007/s00256013-1713-5

[25] Gervaise A, Osemont B, Lecocq S et al. CT image quality improvement using Adaptive Iterative Dose Reduction with wide-volume acquisition on 320-detector CT. European radiology 2012; 22: 295-301. doi:10.1007/s00330-011-2271-7

[26] Schindera ST, Odedra D, Raza SA et al. Iterative reconstruction algorithm for CT: can radiation dose be decreased while low-contrast detectability is preserved? Radiology 2013; 269: 511-518. doi:10.1148/radiol. 13122349 